crystalline solubility relations between $\mathrm{Ni}_{2} \mathrm{TiO}_{4}$ $\mathrm{Zn}_{2}$ TiO, can likewise be explained by the temperature dependence of the degree of 'normalcy' of the ' $\mathrm{Ni}_{2} \mathrm{TiO}_{4}$ ', which does not form a compound at all. At higher and higher temperatures more and more nickel enters the tetrahedral sites, permitting 'nearly pure' $\mathrm{Ni}_{2} \mathrm{TiO}_{4}$ to be prepared in normal structure.

There is still some question as to whether or not all these reactions are reversible and whether we have true second-order phase changes over a wide temperature-range, with the degree of order determined by the temperature.

It is clear from these results that no spinel can be adequately characterized by reference to a table since the temperature and pressure of its formation determine (either stably or metastably) the cation distribution. The results also point to the necessity of presenting temperature-dependent functions for each ion as an essential refinement in crystal field approaches to the problem 4 .

This work forms part of the studies in crystal chemistry supported by the U.S. Army Signal Corps under Contract No. $D A-36-039-S C-85311$.

Ranajit K. Datta

College of Mineral Industries, Rustum Roy

The Pennsylvania State University, University Park, Pennsylvania.

${ }^{1}$ Verwey, E. J. W., and Heilman, E. L., J. Chem. Phys., 15, 174 (1947).

2 Gorter, E. W., Philips Res. Rep., 9, 295, 321, 403 (1954).

${ }^{3}$ Romeign, F. C., Philips Res. Rep., 8, 304 (1953).

Miller, A., J. App. Phys., 30, 24S (Supp.) (1959).

${ }^{5}$ Stubican V., and Roy, Rustum, $Z$. Krist. (in the press).

\section{Reaction of Ethane with a Clean Rhodium Film}

I HAVE observed that when ethane at low pressure (1.2 $\times 10^{-2}$ torr) comes in contact with a $27^{\circ} \mathrm{C}$. rhodium film which was prepared in ultra-high vacuum $\left(1 \times 10^{-9}\right.$ torr $)$, it will decompose to yield gaseous methane and an adsorbed residue with a composition of $\mathrm{CH}_{1.5}$. Others ${ }^{1,2}$ have observed this cracking reaction to occur at temperatures above $160^{\circ} \mathrm{C}$. on metal surfaces of unknown cleanliness.

The rhodium film was prepared in ultra-high vacuum by pulse evaporating ${ }^{3}$ a small coil of 0.005 in. diameter, 99.99 per cent pure rhodium wire in the centre of a 4 in. diameter spherical 'Pyrex' glass reaction vessel which had been baked at $450^{\circ} \mathrm{C}$. for $18 \mathrm{hr}$. The reaction vessel was held at $100^{\circ} \mathrm{C}$. during the film deposition. The average film thickness, measured at the completion of an experiment by $\mathrm{X}$-ray emission spectroscopy, was found to be about $30 \AA$. in most cases. The volume of the system was about 900 c.c.

After the film was deposited, the reaction vessel was isolated from the pumping system by elosing a metal valve (Granville-Phillips Co., Pullman, Washington). Five minutes were allowed for the $0 \cdot 090$-in. diameter filament leads to cool below $100^{\circ} \mathrm{C}$. Mass spectrometrically pure ethane was admitted through a glass break-seal. The pressure in the reaction vessel was followed by a thermocouple gauge which was calibrated against a MoLeod gauge for each gas present and for mixtures thereof. At various intervals, the reaction was quenched by freezing out the ethane in a cold finger with liquid nitrogen and the residual pressure measured.

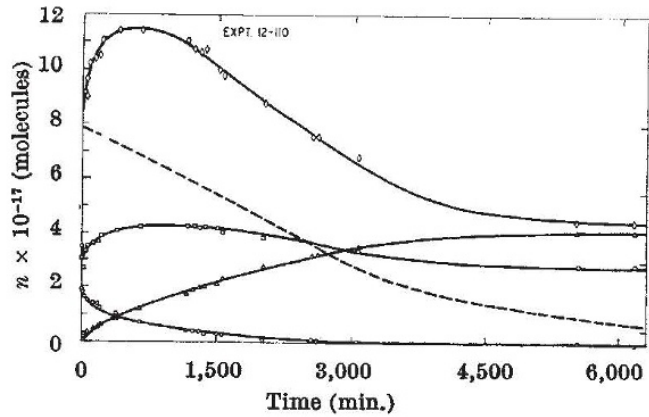

Fig. 1. Rate of decomposition of ethane on a $27^{\circ} \mathrm{C}$. rhodium surface and the rate of product formation. $\mathrm{O}, n \mathrm{C}_{2} \mathrm{H}_{6} ; \Delta, n \mathrm{CH}_{4}$; $\square, n \mathrm{c} ; \Delta, n \mathrm{H},---, H / C$ (surface)

When the liquid nitrogen non-condensable pressure attained a constant value, it was assumed that the reaction had ceased. At this point the gases in the reaction flask were removed and analysed with a mass spectrometer. In all cases only methane was found.

These experiments were also carried out at a film temperature of $100^{\circ} \mathrm{C}$. The films used at $100^{\circ} \mathrm{C}$. were deposited on a $100^{\circ} \mathrm{C}$. glass substrate.

A blank experiment was performed in which ethane was admitted to a baked-out reaction vessel at $100^{\circ} \mathrm{C}$. There was no decomposition after 47 contact hr.

The results from a typical experiment carried out on a rhodium film with an average thickness of $30 \AA$. at $27^{\circ} \mathrm{C}$. are shown in Fig. 1. The number of carbon atoms and hydrogen atoms present on the film at time $t$ were calculated from the initial amount of ethane and the amount of ethane and methane present at time $t$ as determined from the thermocouple gauge readings.

Plotting the log of the ethane pressure against time yielded a straight line. Thus, the disappearance of ethane obeys the first-order rate equation :

$$
\mathrm{d} n_{\mathrm{C}_{2} \mathrm{H}_{6}} / \mathrm{d} t=-k n_{\mathrm{C}_{8} \mathrm{H}_{4}}
$$

with an initial rate constant of $2.13 \times 10^{-8} \mathrm{~min}^{-1}$. The rate of disappearance of ethane on a rhodium film at $100^{\circ} \mathrm{C}$. also obeyed a first-order equation with a rate constant of about $0.5 \mathrm{~min}^{-1}$. The temperature dependence of the initial rate constant gives an Arrhenius activation energy of $16 \pm 1 \mathrm{kcal}$./mole for the disappearance of ethane. The $(H / C)$ surface ratio is about 1.5 at the end of the reaction for both film temperatures. When deuterium was added, the residue desorbed from the rhodium film as deuterated methane, indicating the presence of only monocarbon fragments on the surface.

The addition of oxygen to a clean rhodium film at $100^{\circ} \mathrm{C}$. was found to inhibit the subsequent decomposition of ethane. The rate of disappearance of ethane was decreased by a factor of ten over that for a clean film at $100^{\circ} \mathrm{C}$.

These experiments show that ethane will crack on a clean rhodium surface at room temperature. The rate of reaction is a sensitive function of both the surface temperature and surface cleanliness.

General Electric Research Laboratory, RICHARD W. ROBERTS Schenectady, New York.

${ }^{1}$ Cimino, A., Boudart, M., and Taylor, H., J. Phys. Chem., 58, 796 (1954).

${ }^{2}$ Kemball, C., and Taylor, H. S., J. Amer. Chem. Soc., 70, 345 (1948).

s Hickmott, T. W., and Fhrlich, G., J. Phys. Chem, Solid8, 5, 47 